The Good Lives Model - New directions for preventative practice with children?

Running Head: GLM \& preventing criminality in children

Lucy Wainwright* \& Claire Nee $(*$ Responsible for correspondence)

Psychology Department, University of Portsmouth, Portsmouth, UK

Psychology, Crime \& Law, 2014 Vol. 20, No. 2, 166-182,

http://dx.doi.org/10.1080/1068316X.2013.770851

Full Correspondence address for both authors:

Department of Psychology, University of Portsmouth, King Henry Building, King Henry I

Street, Portsmouth , Hampshire, England, PO1 2DY

Email Address for Corresponding Author: lucy.wainwright@port.ac.uk 


\title{
The Good Lives Model - New directions for preventative practice with children?
}

\begin{abstract}
The study of young offenders has tended to focus on adolescents, despite knowledge that those who are engaging in criminality during childhood are more likely to experience long lasting, life impairing consequences. This qualitative study investigated how child offenders experience the process of desisting from crime. It was hoped that this would provide further insight for those involved with prevention programmes for young offenders. Seven young people aged between ten and eighteen, engaging with the Preventing Youth Offending Project (PYOP) in the UK were interviewed and the data collected was subject to Interpretative Phenomenological Analysis. Four themes emerged from the narratives, all converging on a changed self-identity for those successfully desisting. PYOP aims to enhance the lives of young people and this approach appears to encourage this identity transformation, through the provision of purposeful activity, supported education and mentoring. The increasing popularity of strengths-based, enhancement approaches to rehabilitation such as the Good Lives Model (GLM; Ward \& Stewart, 2003), is discussed in relation to its potential role in the prevention of criminality in young people. It is proposed that the GLM principles could provide essential foundations for early intervention approaches as well as rehabilitative measures for established offenders.
\end{abstract}

Keywords: Childhood, Juvenile offenders, Good Lives Model, Protective Factors, Programme Development. 


\section{Introduction}

As parental control begins to diminish in late childhood and before commitments to work and family develop, criminality is known to peak sharply around age 15 but then reduce again in early adulthood (Piquero, Farrington \& Blumstein, 2007). While the majority of young people will 'grow-out' of crime when they reach adulthood, a small minority will continue offending throughout their adult lives (Moffitt, 1993). This minority will typically begin offending much earlier than their peers, with those who start the earliest having the highest likelihood of a more serious criminal career (Krohn, Thornberry, Rivera \& LeBlanc, 2001). Therefore, it seems that any effort to reduce criminal activity should be grounded in an understanding of why some young people desist when others do not. Yet to a large extent, studies still focus on the reasons for individuals' initial involvement and not on their experience of desistance (Maruna 2001; Laub \& Sampson, 2001). This paper contributes the growing need for further exploration into the process of desistence, and focuses specifically on very young offenders who appear to have the most to gain from desistence (Krohn et al, 2001). In this article we present findings from a qualitative, phenomenological study into the 'lived experience' of being a young offender engaging with an intervention programme in the UK. Further, we consider whether the principles of the Good Lives Model (GLM; Ward \& Stewart, 2003) might be applicable to the prevention of criminality in children.

Early delinquent and defiant behaviour reduces opportunities for children to practice pro-social behaviour and to develop strong relationships and social skills (Loeber \& Farrington, 2001). An associated reduction in motivation for school can often lead to truancy, discipline problems and a disrupted education. This can ultimately weaken a young person's employment prospects, an outcome known to be one of the major risk 
factors associated with criminality (Andrews, Bonta \& Wormith, 2006). Crime prevention and early intervention are therefore critical to prevent today's 'at-risk' children becoming tomorrow's criminals, and all the associated costs. The earlier the intervention, the less chance there is of the young person having extensive contact with the criminal justice system and having serious and/or entrenched criminal behaviour (Allen, 2011). Commendable efforts have been made in relation to 'what works' when treating adult offenders, however much less is known about what is particularly effective with child offenders (Loeber \& Farrington, 2001; McGuire, 2010), and criticisms have been made regarding the interventions currently available for young people in England and Wales (Chambers, Ullmann, \& Waller, 2009).

Rehabilitative efforts with adult offenders have recently seen a shift from a risk and deficit-based model of criminality to those that also incorporate the strengths of the individual, with the GLM being a good example of this (Ward, Yates \& Willis, 2012). This shift in focus derives from a belief that offenders need something to motivate them more effectively towards a life without crime (Ward \& Stewart, 2003). Though controversial to more punitive ideologists, Ward and Stewart reason that by equipping offenders with skills, capacities and opportunities for living a more fulfilled life, individuals are less likely to perceive crime as a worthwhile or potentially necessary exercise (Ward, 2002). Within therapy, a 'Good Lives Plan' is constructed between therapist and offender which is personally relevant to the offender's own values and identity, and provides a greater sense of cohesion in his or her life (Ward \& Maruna, 2007). Such a method should also simultaneously reduce the dynamic risk factors (or criminogenic needs) which are well established in the related psychological literature. 
The GLM therefore has two primary goals, to enhance well being as well as to reduce risk of offending (Ward, Yates \& Willis, 2012).

The rationale for enhancement as a form of intervention is rooted in Deci and Ryan's (2000) 'Self-Determination Theory of Needs', which defined all humans as inherently active organisms seeking three basic psychological needs; Relatedness, Competence and Autonomy. Arnhart (1998) reflected that this is not limited to particular cultures, but that such "natural desires" will be similarly evident within every human society in history. Individuals seek to satisfy these needs not only as a means of acquiring a fulfilling life overall, but because each need is fulfilling in itself (Ward \& Maruna, 2007) and as such, will be inclined toward supportive frameworks for these needs (Deci \& Ryan, 2000). The Self-Determination Theory is applicable to a wide range of human behaviour with researchers investigating how the fulfilment (or otherwise) of basic psychological needs might affect such things as college satisfaction (Filak \& Sheldon, 2003), intimate relationships (La Guardia \& Patrick, 2008), and various forms of psychopathology (Ryan, 2005; Moller \& Deci. 2010). When these needs are not being met, due to supportive relationships being unavailable, or when opportunities for learning or making independent decisions are thwarted, individuals will be drawn to alternative methods of meeting them, including offending (Ward \& Stewart, 2003). Ward and Maruna (2007) stress that rehabilitation with no clear focus on achieving a good life will only provide some of the conditions needed for change, rather than the essential inspiration and drive necessary for maintaining a pro-social future.

Ward and Colleagues have furthered Deci and Ryan's (2000) theory, proposing 11 more specific 'primary goods' as necessary for optimum well being and important in terms of rehabilitative practice (Ward \& Gannon, 2006). However, Deci and Ryan's (2000) three 
fundamental needs of Relatedness, Competence and Autonomy still feature within this more evolved model. Therefore, at a rudimentary level it would be reasonable to suggest that early intervention strategies should at the very least assist young people in securing the three very basic psychological needs proposed by the Self-Determination Theory (Deci \& Ryan, 2000) and embraced by the GLM. Empirical evidence stemming from research on the development of criminality would support this notion, since young people's relationships, competencies and personal autonomy have long been shown to affect their involvement in crime.

Discussion of the link between relatedness and criminality has been ongoing for generations. Positive peer relationships provide emotional support and promote developmental functioning (Bender \& Losel, 1997). For these reasons, poorly developed social relationships are said to be highly predictive of offending behaviour (Loeber \& Farrington, 2001). Competency also features within the research literature relating to child offending. For example, a low IQ has long been established as a risk factor (Farrington and Welsh, 2007), with low intelligence measured at age 3 significantly associated with offending up to age 30 (Stattin \& Klackenberg-Larsson, 1993). Competence in problem solving or social skill can also act as a protective factor for young people (McGuire, 2005), and even belief in competence is predictive, since people with high assurance in their capabilities approach difficult tasks with more determination than those without (Bandura, 1994). The last of the fundamental needs proposed by Deci and Ryan (2000); autonomy, has perhaps some of the most compelling evidence linking it with offending. Indeed, in a phenomenological study of 65 offenders, Maruna (2001) proposed that offending may be an effort to demonstrate personal agency and control when it is seen to be lacking elsewhere. For young people, 
it has been posited that 'edgework' (or risky behaviour) can provide the means of achieving this sense of independence (Wood, Wilson \& Cochran, 1997). Indeed, a sense of independence has been classified as a protective factor for some 'at-risk' young people, as they are less likely to enter anti-social peer groups and make more productive life choices with regard to education and employment (Blum, 1998).

Most rehabilitation techniques do not routinely draw on the importance of narrative identity (Maruna, 2001). Yet Maruna's work highlighted the crucial role of developing a coherent, plausible and pro-social identity when desisting from crime. Offenders lacking a clear narrative identity (or indeed possessing a maladaptive identity) will be more likely to continue offending as they will not be able to envisage a more positive future. A focus on the development of a pro-social identity seems especially relevant to early adolescent offenders, since individuals in this age group are said to be on the verge of negotiating an identity crisis (Erikson, 1950), with either achievement or confusion as the potential result. Erikson (1968) notes that during this crisis, adolescents are simultaneously encountering situations whereby they are forced to enhance their agentic abilities, strengthen skills and manage social obstacles successfully; the same three components essential for optimum well-being (Deci \& Ryan, 2000).

In recent years, a body of empirical evidence has accumulated on the construction and content of possible selves for the future, with reference to the self-regulatory nature and motivational influence of these possible selves, particularly in relation to behaviour and delinquency (Hoyle \& Sherrill, 2006; Oyserman, Bybee \& Terry, 2006). Conversely, a pessimistic future orientation has also been empirically linked to problem behaviours in young people (Robbins and Bryan, 2004). In terms of preventative practice, it therefore 
seems entirely appropriate to provide some assistance to young people in formulating a positive, non-criminal identity to take into adulthood.

Interventions for very young offenders are rare in the UK and suitable evaluations of these interventions are rarer still (Ross, Duckworth, Smith, Wyness \& Schoon, 2010). One UK based intervention which has yielded favourable evaluation results however is a community-based (non-residential) programme; The Preventing Young Offender Project (PYOP). Referrals to the programme come from social workers, the local Youth Offending Team (YOT), the Education Department, a local community safety partnership, parents and from participating offenders themselves. The criteria for referral and acceptance onto PYOP (in line with Youth Justice Board recommendations) are those classed as Prolific offenders, defined through the national Youth Offending Information System database (YOIS) as anyone with 10 offences in 12 months or anyone facing a custodial sentence; Offenders with highly specialised offending needs, such as sex offenders; Preventative/protective referrals for young people between 7-12 (known to be offending by the local police and the project coordinator).

PYOP provides individualised, holistic support by trained project workers, which may include some or all of the following;

- One-to-one mentoring for reintegration into education, anger management and constructive use of time

- Group-work for antisocial behaviour; problem-solving; anger management; victim awareness; interpersonal skills; substance misuse; appropriate sexual behaviour; and health issues 
- Music, art and drama workshops as well as outdoor activities to develop selfesteem, healthy competition and interpersonal skills.

Where needs are identified that cannot be addressed by staff at PYOP, other agencies are called upon. Support for families is provided where necessary such as counselling and skills training. Further, siblings are offered the same services as the child offenders to reduce negative competition. Children and adolescents are welcome to remain involved in the programme for as long as they personally feel necessary, and a surprisingly high number chose to be involved for 18 months or more. The programme aimed to be fully responsive, with no two intervention plans being identical but subject to participant's individual needs, strengths and current circumstances. Therapists using a GLM approach also collaboratively tailor individualised intervention plans, the aforementioned Good Lives Plans, with offenders to suit their narrative identities. In a more explicit way than PYOP, the GLM takes into consideration the weightings an offender gives to the different primary goods, the strengths they may possess to help them achieve their goals and the obstacles they may face in achieving them (Ward \& Maruna, 2007).

Nee and Ellis (2005) conducted the first evaluation of PYOP using an established risk assessment tool, the LSI-R (Andrews \& Bonta, 1995), to show highly significant reductions in participants' criminogenic risk and actual offending behaviour over time. There were also strong indications that the level of offending behaviour had decreased during the intervention, in comparison with the control group which was unchanged in terms of risks, needs or offending rate. To complement Nee and Ellis (2005), a qualitative study was considered worthwhile to further enhance our understanding of 
young people's experiences of PYOP. We concur with the view that young people 'atrisk' of criminality should very much be considered as 'part of the solution, not just part of the problem' (Lyon, Dennison \& Wilson, 2000). However, despite them being the key to understanding how to move forward, it is still surprisingly unusual to canvass the views of those participating in interventions (Nee, 2004). We took a largely exploratory standpoint on approaching this study, to understand more about how PYOP was experienced and how this programme might aid the process of desistence in a small sample of PYOP participants. It is our belief that this will benefit not only our academic understanding, but also highlight important areas for further research regarding interventions.

\section{Method}

\section{Participants}

Seven participants, (aged 10,14, 14, 15, 16, 18, 18) took part, all of whom had commenced criminality before adolescence. Participants were recruited from PYOP via letter and key worker contact on an ad hoc basis (i.e. the first seven that contacted the researcher). While the sample size is small, our aim was to provide a detailed interpretative account of a few willing participants who had experienced PYOP and chose to use Interpretative Phenomenological Analysis (IPA; Smith,1996) to do this. Studies using IPA are conducted with a small sample sizes so that the individuality can be retained, and proponents of the method have argued that just one participant is sufficient for an interesting study (Smith, 2004). 
All participants had experienced substantial contact with PYOP, with an average of 5.2 years of intervention. All participants were male, Caucasian and living in the Portsmouth area. Six of the seven participants could be described as having desisted from offending, which became apparent after their recruitment, through both their own assertions and those of the project coordinator. However, it is not possible to give an exact time relating to how long they had desisted for due to the fact desistence is a complex process (Maruna, 2001). To ensure the anonymity of the interviewees, each participant is given a pseudonym throughout.

\section{Procedure}

\section{Interview Process}

All interviews were conducted in an environment familiar to the young people to ensure they were uninhibited and comfortable. Two young people chose to include their support workers in the interview process and one mother was also involved. This was seen as appropriate for the younger interviewees.

In line with the principles laid out by Smith (1996), semi-structured interviews were used to gather information about participants' experiences. All participants were asked about the following areas; their experience of offending behaviour (i.e their reasons for initial involvement and their feelings throughout any act of criminality), their experience of engaging with PYOP (i.e. what they found useful or difficult), and their experience of desisting (where appropriate, such as their inspiration for cessation and any associated struggles or successes). While participants were free to describe whichever experiences of PYOP, offending and 
desistence they chose, most interviews were heavily focused on participants' experience of desistence by their own choice. It was important to allow participants to determine the focus of the interview, allowing what Smith and Osborn (2003) call 'novel avenues', in order to appreciate the phenomenology of their realities rather than imposing the researchers reality onto them. Ethical guidelines were followed including informed consent, the right to withdraw from the study, anonymity, and full debriefing post interview. There were no time constraints on the interviews, but all interviews were conducted within 30 minutes. This was due to participants becoming restless, distracted, having limited time with their support workers or due to interruptions at the PYOP centre. However, in all cases, participants remained after the interview and continued in an informal discussion.

\section{Process}

All interviews were audio-taped and transcribed verbatim by the investigator only, with certain proper nouns omitted. Interpretative Phenomenological Analysis (IPA) was utilised because our own aims seemed to fit well with the philosophy of the approach in that we wanted to understand 'lived experience' and how participants personally make sense of their experience (Smith \& Osborn, 2003). Our aim was not to produce an objective record of exactly what participants experienced at PYOP, but to give a subjective record of the participant's thoughts and feelings about it, eliciting important themes from participants and forming alliances between them. This necessarily makes the analysis subjective in nature, and indeed forms the 'interpretive' part of the process alongside the 'phenomenological'. This approach is deemed suitable for research of a difficult and personal nature (Kay \& Kingston, 2002) and has become a popular method 
for analysing personal accounts for small samples in recent years (Smith, Flowers \& Larkin, 2009). IPA was also chosen as a method due to the way it frames the participant as an expert in the subject area, which we feel is in line with our own perspective that these young people are in a position to inform researcher and policy makers of what works and what does not work.

Each individual transcript was reviewed several times before analysis took place to ensure familiarity. Interesting and indicative responses were then noted in the left hand margin, with potential themes noted in the right hand margin. Similarities between participants' themes and any emerging interconnections were then considered in line with Smith's (2004) recommendation to "imagine a magnet with some of the themes pulling others in and helping to make sense of them." (p.71). IPA acknowledges the need for active interpretative activity on the part of both the participant and the researcher, due to the fact it is not possible to fully appreciate the experience under investigation in exactly the same way as the participant (Eatough, Smith \& Shaw, 2008). The researchers assisted the process to identify any potential themes overlooked and areas where the researcher may have unwittingly imparted previous assumptions and biases (Smith \& Osborn, 2003). Inter-rater agreement was reached on $85 \%$ of master themes and only those with mutual agreement have been included within the paper.

\section{Results \& Discussion}

While each participant was given the freedom to chose personally relevant experiences during interview, most discussions corresponded well with the three fundamental needs of Self-Determination Theory (Deci \& Ryan, 2000), also represented within the GLM 
(Ward \& Stewart, 2003). Four master themes emerged from the narratives with one theme, self-identity, assuming both a salient and influencing position over the other three. For the purpose of this report, these three other themes; social awareness; selfdevelopment; and self-hope will be expanded upon in greater detail, with the theme of self-identity being interwoven into each.

\section{Social-Awareness}

Despite being essentially a private construct, self-identity is socially constructed and modified (Goffman, 1959), namely by the peer group in adolescence (Harris, 1998). Indeed, all but one of the young people in this study discussed the overwhelming importance of their peer relationships. It is well established that reputation, popularity and power among peers has real significance for adolescents, especially when exploring possible identities (Sica, 2009). It is little surprise therefore that these same six participants also discussed the pressure they felt to conform to their peers' expectations, with this comment by Martin being highly representative of participants' experiences;

My friends put pressure on, and then I do it

Martin focussed heavily on the respect he feels he has earned within his peer group, accepting the inescapability of conforming. However, most participants alluded to making an active choice to offend, rather than feeling powerless like Martin. In Craig's case, he was seeking a particular status within the group, concurring with Brezina's (2000) proposition that delinquency is a very calculated method of solving a social problem. Craig is very transparent when discussing the perks of committing crime in terms of social acceptance when he describes the day after being arrested for shoplifting. 
I got into school the next day, all the boys were saying, oh well done, that's well cushdy [good]

Through conforming, both Martin and Craig are able to demonstrate an identity, however negative it may seem to those following a more conventional route, which is fostered within an offending group. In contrast, to oppose or desist from anti-social behaviour begins a process of alienation for young people whereby they are stripped of their identity as a group member. This can be particularly distressing for young people already in a state of identity crisis (Erikson, 1969). This is exemplified by Dave who had not yet stopped offending, when he explained that he actively chose not to associate with a non-deviant group, whom he labelled as 'gimps'. Even forming loose associations with this 'out group' could lead to rejection from his peer group:

'I'd get terrorised if I was seen with them'

The potential label of a 'gimp' is disparaging and would understandably cause embarrassment for those trying to desist from offending, and may therefore deter delinquent young people from trying. Dave's description of non-offending peers as 'gimps' represents an interesting variation of labelling theory (Becker, 1963), whereby young people who are vulnerable to receiving the label 'criminal' distribute labels to others, possibly to reinforce not only the group's identity but their individual place within it.

It is clear that peer relationships, so intensely valued by the young people in this study, can also be detrimental. Relationships appear bolstered by an act of anti-social behaviour, yet threatened by an act of self-redemption. While Andrews and Bonta (2006) certainly recognise the importance of social relationships in their Risk-Need- 
Responsivity model, the complications of 'reducing' criminal peers and 'enhancing' non-criminal peers warrant particular consideration in relation to social identity.

According to the GLM, the peer relationships described by these participants are not sufficient to satisfy the human need of 'relatedness'. Instead, relationships built on trust and respect would satisfy this need. In reality, young people in this study did not consider their peer groups to be appropriate sources of advice or guidance, but instead turned to the mentors and support workers provided by PYOP, known to benefit adolescents in their development (Tarling, Burrows \& Clarke, 2001). All participants considered the recruitment of mentors and support workers to be complex, with the concept of 'understanding' being fundamental to the role of a mentor. Ben discusses this powerfully when giving recommendations for PYOP:

'Pick the right staff... Be like us when they were younger, know what it's like.... Done the stuff that we've done, been in care.... cos a lot of people wouldn't have a clue'

Just as policy makers have been criticised for creating a dramatic distinction between themselves and offenders, Ben is creating a similar 'Us and Them' division. Yet, Ben highlights the necessity of such a distinction, as he believes those who have successfully managed similar criminogenic risks are in a strong position to advise those who are struggling to do likewise. This brings an added dimension to the word 'relatedness', since the mentor is able to relate personally with what the young person is experiencing. Bandura (1994) stressed the need for vicarious role models to be present during adolescence, who are seen as similar to the young people but also as possessing competencies to be sought after. This raises the young people's beliefs that they too possess the capabilities to succeed in life and this therefore strengthens self-efficacy. 
The theme of 'Social Awareness' has shown how young people lacking a supportive, non-criminal peer group can benefit substantially from strong, trusting relationships formed with their support workers who provide guidance and can be trusted. These strong relationships go some way to fulfilling the basic human need of 'relatedness' (Deci \& Ryan, 2000; Ward \& Stewart, 2003) thereby contributing to overall well-being and hopefully to desistence. A particularly insightful comment made by an ex-gang member succinctly weaves this discourse with the next, which relates to participating in purposeful activity; "Kids can walk around trouble, if there is some place to walk to, and someone to walk with" (McLaughlin, Irby and Langman, 1994, pg 219).

\section{Self-Development}

Self-efficacy is not only gained through supportive relationships, as mentioned in the previous theme, but is also boosted as individuals learn and master new skills (Bandura, 1994). Unfortunately, it has been found that young offenders spend an excessive amount of time engaging in 'passive leisure' activity rather than anything productive (Farnworth, 2000). Martin stressed the importance of worthwhile activities in reducing criminality, stating that the area in which he lives has little to offer:

'there's not much for teenagers to do that's why they gets in a lot of trouble'.

Again, there is an element of avoiding responsibility in Martin's statement. He is suggesting that young people are almost forced into offending because they have not been presented with alternative options. However, displacing responsibility was not an uncommon position, and Liam reasons that his offending was a result of limited activities: 'I was bored'. Similarly, Craig gave boredom as the fundamental cause of young offending: 
"his mate says 'oh I'm bored' and he says 'yeah, I'm bored as well' and then they go out and cause trouble, to waste the time.'

'Boredom-inspired offending' could be significantly more problematic following an exclusion from mainstream education, due to growing associations with other excluded young people and minimal organised activities. However, Dave gives a further rational explanation for offending:

'I like it...doing crime'

To give up any enjoyable pastime, there needs to be sufficient negatives present to outweigh the positives (Cornish \& Clarke, 1986). In Dave's life, the balance is not yet in favour of desistence and he accepts periods of incarceration in exchange for the 'prestige' crime gives him within his peer group. At this stage in his life therefore, he sees little reason to stop. Craig provides further understanding of the appeal of crime:

I suppose you get a thrill from it too. I mean, when I was stealing from the shop, as I was running away, I did feel invincible

Craig admitted to feeling belittled when he was ultimately caught by police, as his thrill seeking had led to him developing a distorted view of his abilities to avoid capture. Nonetheless, he had felt excited and untouchable on a regular basis prior to capture. Craig's sense of power was most likely reinforced by the fact he was running away in a public area, and was thus the centre of attention. This experience of euphoria evokes images of a roller coaster, an analogy researchers have also used when exploring abusing intimate relationships (Horely, 2002). Crime may provide opportunities for experiencing intense highs, which may counter the more intense lows which many young offenders may have experienced over their life course (Jacobson, Bhardwa, Gyateng, Hunter \& Hough, 2010). This statement also substantiates Cushman's (1990) 
concept of the empty self, which instead of being fulfilled with more long lasting accomplishments, is periodically satisfied by the type of immediate thrills described by Craig. More worthwhile activities can reduce the need for such instant gratification, such as those provided by PYOP to develop young people's interests, talents and education. These activities appeared to expand the young people's horizons by engaging them in new and constructive activities, which in turn builds relationships between them and responsible adults based on earned trust and respect. Subsequently, new opportunities develop for alternative lifestyles and thus both relatedness and competence can be achieved (Deci \& Ryan, 2000; Ward \& Stewart, 2003). Martin highlights the change in his behaviour since PYOP;

'I've got better things to do. You can't be bothered with it. Don't need the same buzz cos you've got something else' (Martin, Pg 6, lines 18-19)

Martin can confidently say he has reached a part of his life where the requirement for a 'buzz' is not overwhelming, and can be replaced by a whole range of other activities, from the mundane to the exciting. He now experiences (and is in control of) a more fulfilled life, which he does not jeopardise. Similarly,

'most criminals do it for the excitement and it's not really an excitement' (Craig, Pg 6,

Lines 11-12)

This generalised statement is important as is signifies the shift Craig has made from an offender to a non-offender identity. When Craig was offending, short-term gratification was satisfying and he sees this as a characteristic of most offenders. He is now looking at this characteristic with hindsight and a new perspective, one which has developed as part of his new identity as a non-offender. 
Nonetheless, it is a concern that within PYOP, individuals are given the choice of which activity to pursue and for how long. This approach misses opportunities to achieve more difficult targets, and therefore enhance self-efficacy through psychologically rewarding activities, such as counselling. Here, Andy talks about anger management:

I only kept that up for 2 or 3 weeks cos I found it wasn't at all of an interest'

The potential of PYOP to impact on a young person's future was discussed by Martin who felt that in areas where the advantages of gainful employment are not obvious, there is little motivation to learn and develop. Martin recommends the opening of 'little factories' to give young people direction and drive by making them think about their futures:

'They might think, I like doing that... Then they might think yeah I'll go to college and do something on it'

Prior to PYOP, interviewees were predominantly 'bored', and seeking entertainment. As a consequence of this, crime seemed inviting, and something which they could retain some control over. PYOP provides its participants with activities in which they can gain skills and a sense of 'competence', the second basic human need advocated in the SelfDetermination Theory and one of the 11 primary goods outlined in the GLM. For the most part, these activities diverted attention from criminality. This was more than a situational method of crime prevention however, as it opened opportunity and aspirations for the future. Maruna (2001) found that the active offender group he interviewed saw little hope for change in their lives, differing drastically from the more optimistic desisters. This sense of purpose in young people is now examined. 


\section{Self-Hope}

Over a century ago, William James (1890; cited in Oyserman \& James, 2011) wrote how future orientation helps to focus motivational attention and guide behaviour, as well as allowing the individual to respect him or herself. Therefore, Martin's suggestion of supplying young people at PYOP with 'little factories' (as seen in the previous theme) to support their ambitions seems worth exploring. While PYOP does not actually provide such facilities, it has undoubtedly assisted the young people in this sample to construct a vision for their future. This is in contrast to their lives prior to PYOP, which is demonstrated by Andy's pessimistic view of his future before the intervention.

'Well, when I was younger, I never thought I would achieve any G.C.S.E.s [General Certificate of Secondary Education qualifications]'

Andy's bleak outlook of his academic potential stands in remarkable contrast to interviewees' present stance regarding their goals and ambitions. Three interviewees had a career in mind, a conceptualisation of their possible self, and were determined in this pursuit. Liam had the ambition to be a coach driver, while Craig had set the goal of joining the military police. It was interesting to see that both had chosen careers containing an element of power and control, illustrated in the following quotations:

'Cos they're big and long and heavy' (Liam)

'They've got more power than the normal police' (Craig)

Craig's comment about becoming more powerful than the 'normal' police represents the extent of his changed identity, in that he will no longer be under the control of the 
police, but can potentially be in control of them. In addition to these, Ben had made a career choice and was pursuing a college course to become a plumber. When talking about the financial advantages of plumbing, he admits:

Yeah that's why I thought I'd do it...

Money is a form of social power within the developed world, and thus Ben has also embarked on a quest for a powerful role. Although a very different choice, when asked what he wanted to be, Dave answered 'a career criminal', a career associated with negative power. Maruna (2001) would argue that Dave is protecting his ego by not striving for a target he may not achieve, thought to be less damaging to the self concept than an experience of trying without success. Offending behaviour was not a part of the future possible selves most individuals had created. They implied the use of a psychological balance sheet in comparing a life of crime with their new identity:

'It's not worth it to me really. It's a waste of time' (Craig)

'I just didn't feel like stealing was worth....it wasn't worth the trouble with the police and that' (Andy)

Craig demonstrates that he has come full circle, in that previously, he would commit crime 'to waste the time', he now considers it a 'waste of time'. He now understands that time can be used productively and is valuable to him in preparing for his future self. Andy's balance sheet is also in favour of a non-offending future. Liam holds a different view, arguing that despite his life seeming 'better before' PYOP, he recognised that this was not ultimately going to lead to a happy life and therefore he was prepared to sacrifice some degree of entertainment for the advantages of not committing crime. 
In line with the findings of Oyserman et al (2006), participants seemed motivated to take part in activity which would assist in the fulfilment of their future self, but anxious to avoid activity which might harm it. Young people are keen to emphasise their own role in desisting from crime, rather than allowing PYOP the credit, an important theme found by Lyon at al (2000) when interviewing young people in custody;

'I don't think that PYOP had any impact anyway' (John)

Young people in this study support a finding by Maruna (2001) that people who have desisted from crime demonstrate an almost exaggerated sense of control over their lives, which is remarkable given the total lack of control many offenders feel whilst offending. Indeed, narratives of persisting offenders were noted as being five times more likely than desisting offenders to ignore any 'language of agency' (Larson, 2000). Andy shows a belief that he is in control of his own behaviour, and that it his personal choice, rather than an imposed choice, to not thieve:

I just stopped and I've not gone back into a shop to steal since.

This realisation is likely to be life changing for a young person who will experience a sense of empowerment with this control. It is perhaps the time when the need 'autonomy', is fulfilled to the same extent as relatedness and competence (Ward \& Stewart, 2003). The acceptance of personal responsibility, or the development of an internal locus of control, seems to be a crucial part of any rehabilitation process. Without such a responsibility, offenders will continue to see themselves as having no control and as a passive observer in the events which shape their lives. Active offenders in Maruna's (2001) sample made substantially less connections between their internal actions and ultimate outcomes, were more likely to suggest 'winning the lottery' as a personal striving. At present, Dave has not developed an internal locus of control, 
giving this response when asked to define himself:
D: $\quad$ Coiled spring
I: What sets you off?
D: Anything
I: What holds you down, doesn't let you spring?
D: $\quad$ Nothing

His reference to a coiled spring implies he is out of control. He can react in anyway, to anyone or anything. He feels that under no circumstances can he do anything to predict his behaviour.

Overall in this section, the young people appear to have made a journey from a self with no prospects to a self with some ambition and direction. This developing sense of 'autonomy' is the third need in the Self-Determination Theory and an important primary good within the GLM (Ward \& Stewart, 2003). Mostly, they accept personal responsibility for achieving ambitions in life and as a consequence, to establish a future self in relation to what they have learned with a revived sense of motivation.

\section{Conclusions}

We set out to understand more about young people's experience of PYOP and how this may or may not contribute towards desistence from offending. From the results, we propose that the experience of PYOP aids in a cycle of desistence, which consists of three key stages; improving their social awareness, achieving some sense of selfdevelopment and consequently establishing self-hope. At each of these stages, one or 
more of the fundamental needs highlighted by Deci and Ryan (2000) is also fulfilled, which buffers against criminality (Ward \& Stewart, 2003). Importantly, all three stages also contribute to the construction of a positive future identity for the young person involved. Having gained a sense of responsibility, as well as the necessary skills and supportive relationships with PYOP, this future identity is seen as achievable and motivating.

The theoretical principles of the GLM are increasingly being incorporated into interventions for incarcerated adult offenders in the UK (Riddy \& Harris, 2010) and across the rest of the world (Laws \& Ward, 2011; McGrath, Cumming, Burchard, Zeoli \& Ellerby 2010). However, evidence within this paper suggests that the scope of this rehabilitative model could potentially be extended to prevent against criminality in the first instance (or at least desist from it before it becomes detrimental to the individual's future). A future step would be for researchers to evaluate and build on these findings with larger samples of desisting offenders.

Sadly however, enhancing the lives of disruptive young people is something that provokes fierce public reaction, certainly in the UK. The British Broadcasting Corporation (BBC) facilitated an online message board on $17^{\text {th }}$ August 2011, several days after riots erupted in major English cities and punitive conservatism dominated. These selected comments were representative of many;

'the do-gooders want to go easy on wrong-doers. Sometimes I could scream with indignation'

'Let the people vent their anger and exact their revenge by unleashing a hoard of rotten vegetables in their faces, thereby, humiliating these thugs, murderers, looters and 
rioters'.

As political debates ensue regarding the role of poverty and limited opportunity, the proposals we make are as necessary as ever. Results from a large scale study using a cross-sectional sample of young people in the USA indicated that economic and neighbourhood variables were actually less strong predicators of future delinquency than feelings of future certainty and supportive family functioning (Caldwell, Wiebe \& Cleveland, 2006). When all they see is a bleak future, some young people have little to lose through offending.

Rather than simply criticising schemes like PYOP and believing them to reward bad behaviour, it is surely a priority to encourage in all children, regardless of whether they satisfy a list of 'risk and need' criteria in relation to their offending, a strong sense of self, secure and trusting social relationships, purposeful activity and ambition. Perhaps this is idealistic, but the fact remains that enhancing young people's lives will have a positive impact on own their choices and opportunities as an adult as well as a positive impact on society. Ward and Marshall (2007) make a poignant statement; "Offenders are psychological agents who want what most of us want, a chance at a life that expresses their fundamental commitments and hopes, an opportunity to live a meaningful and rewarding life" (p 296). If the public are keener on retribution for our established offending population, then providing these opportunities to children before offending has become established must surely be a less resisted, less expensive, and yet more rewarding answer. 


\section{References}

Allan, G. (2011). Early intervention: The next steps. London: DfE

Andrews, D. A., \& Bonta, J. (1995). The Level of Service Inventory - Revised. Toronto: Multi-Health Systems

Bandura, A. (1986). Social foundation of thought and action: a social cognitive theory.

Eaglewood Cliff: Prentice Hall

Bandura A. (1993). Perceived self-efficacy in cognitive development and functioning. Educational Psychology., 28, 117 - 148

Becker, H. S. (1963). Outsiders: Studies in the Sociology of Deviance. New York, NY: The Free Press

Blustein, D. L. \& Phillips, S. D. (1990). Relation between ego identity statuses and decision-making styles. Journal of Counselling Psychology, 37, 160-168

Blum, R. (1998). Healthy youth development as a model for youth health promotion: A review. Journal of Adolescent Health, 22, 368-375

Brezina, T. (2000) . Delinquent problem solving: An interpretive framework for criminological theory and research. Journal of Research in Crime and Delinquency, 37, 3-30

Caldwell, R., Wiebe, R., \& Cleveland, H. H. (2006). The Influence of Future Certainty and Contextual Factors on Delinquent Behavior and School Adjustment among African American Adolescents. Journal of Youth and Adolescence. 35, 587-598

Chambers, M., Ullmann, B., Waller, I., (2009) Less crime, lower costs: implementing effective early crime reduction programmes in England and Wales, London: Policy Exchange

Cornish, Derek \& Clarke, Ronald V. (1986). "Introduction" in The Reasoning Criminal. Cornish, Derek and Ronald Clarke (eds.). New York: Springer-Verlag. pp 1-16 
Cushman, P. (1990). Why the self is empty. Toward a historically situated psychology. American Psychologist. 45(5), 599-611

Eatough, V., Smith, J.A. \& Shaw, R.L. (2008). Women, anger and aggression: an interpretative phenomenological analysis. Journal of Interpersonal Violence, 23(12), 1767-1799.

Erikson, E.H. (1950). Childhood and Society. New York: Norton

Erikson, E.H. (1968). Identity: Youth and Crisis. New York: Norton

Farnworth, L. (2000). Time use and leisure occupations of young offenders. American Journal of Occupational Therapy, 54, 315-325

Farrington, D., \& Welsh, B. (2007). Saving Children from a Life of Crime. New York: Oxford University Press

Filak, V. \& Sheldon, K. M. (2003). Student psychological need satisfaction and college teacher-course evaluations. Educational Psychology, 23, 235-247

Goffman, E. (1959). The presentation of self in everyday life. Garden City, NY:

Doubleday Anchor

Harris, J. R. (1998). The nurture assumption. New York: Free Press

Hemphill S.A., Toumbourou J.W., Catalano R.F., Mathers M. (2004). Levels and family correlates of positive adolescent development: A cross-national comparison. Family Matters, 68, 2-8

Horely, S. (2002). Power and Control. Why charming men can make dangerous lovers. Reading, Berks, Cox \& Wyman

Hoyle, R. H., \& Sherrill, M. R. (2006). Future orientation in the self-system: Possible selves, self-regulation, and behavior. Journal of Personality, 74, 1673 - 1696

Jacobson, J., Bhardwa, B., Gyateng, T., Hunter, G. \& Hough, M. (2010). Punishing Disadvantage - a profile of children in custody. London: Prison Reform Trust 
Krohn, M. D., Thornberry, T. P., Rivera, C. \& LeBlanc, M. (2001). Later Careers of Very Young Offenders. Pp. 67-93 Loeber, R. \& Farrington, D. P. (eds.), Child Delinquents: Development, Interventions, and Service Needs. Thousand Oaks, CA: Sage

La Guardia, J. G., \& Patrick, H. (2008). Self-determination theory as a fundamental theory of close relationships. Canadian Psychology, 49, 201-209

Laws, D. R. \& Ward, T. (2011). Desistance from sexual offending: Alternatives to throwing away the keys. New York, NY: Guilford Press

Loeber, R. \& Farrington, D. P. (Eds.) (2001). Child Delinquents: Development, Intervention and Service Needs. Thousand Oaks, CA: Sage

Lyon, J,. Dennison, C. \& Wilson, A. (2000). 'Tell Them So They Listen': Messages from Young People in Custody. Home Office Research Study 201. London: Home Office

McGuire, J. (1995). What works: Reducing reoffending: Guidelines from research and practice. Wiley series in offender rehabilitation. Oxford, England: John Wiley \& Sons

McGuire, J. (2005). Social problem-solving: basic concepts, research and applications. In M. McMurran and J. McGuire (eds). Social Problem Solving and Offenders: Evidence, Evaluation and Evolution. Chichester, John Wiley \& Sons

McGuire, J. (2010). Comparing coercive and non-coercive interventions, Transitions to Adulthood vol 2. London: Centre for Crime and Justice Studies

McLaughlin, M., Irby, M., \& Langman, J. (1994). Urban sanctuaries: Neighborhood organizations in the lives and futures of inner-city youth. San Francisco: JosseyBass 
Maruna, S. (2001). Making Good: How Ex-Convicts Reform and Rebuild Their Lives. Washington, DC: American Psychological Association

Moffitt, T. E. (1993) "Life-course-persistent" and "Adolescence-limited" antisocial behavior: A developmental taxonomy. Psychological Review 100, 674-701

Moller, A. C., \& Deci, E. L. (2010). Interpersonal control, dehumanization, and violence: A self-determination theory perspective. Group Processes \& Intergroup Relations, 13, 41-53

Nee, C. (2004). The offender's perspective on crime: methods and principles in data collection. In A. Needs and G. Towl (Eds.), Applying psychology to forensic practice. London: BPS Blackwell

Nee, C. and Ellis, T. (2005) Treating Offending Children: What Works? Legal and Criminological Psychology, 10, 1-16

Oyserman, D., Bybee, D., \& Terry, K. (2006). Possible selves and academic outcomes: How and when possible selves impel action. Journal of Personality and Social Psychology, 91, 188-204

Oyserman, D. \& James, L. (2011). Possible Identities. In S. J. Schwartz, K. Luyckx, \& V. L. Vignoles (Eds.), Handbook of Identity Theory and Research. New York: Springer

Riddy, R. \& Harris, D. (2010). Thinking Skills Programme Theory Manual. Ministry of Justice: London

Robbins, R. N. \& Bryan, A. (2005). Relationships Between Future Orientation, Impulsive Sensation Seeking, and Risk Behavior Among Adjudicated Adolescents. Journal of Adolescent Research. 19(4), 428-445 
Ryan, R. M. (2005). The developmental line of autonomy in the etiology, dynamics, and treatment of borderline personality disorders. Development and psychopathology, 17, 987-1006

Ryan, R. M., \& Deci, E. L. (2000). Self-determination theory and the facilitation of intrinsic motivation, social development, and well-being. American Psychologist, $55,68-78$

Sampson, R. J. \& Laub, J. H. (1993). Crime in the Making: Pathways and Turning Points through Life. Cambridge, MA: Harvard University Press

Sica, L, S. (2009) Adolescents in different contexts: The exploration of identity through possible selves. Cognition, Brain, Behavior. An Interdisciplinary Journal, 13, 221252

Smith, J.A. \& Osborn, M. (2003) Interpretative phenomenological analysis. In J.A. Smith (Ed.), Qualitative Psychology: A Practical Guide to Methods. London: Sage Tarling, R., Burrows, J. and Clarke, A. (2001) Dalston Youth Project Part II (11-14): An Evaluation, Home Office Research Study No. 232, London: Home Office

Ward, T. (2002) Good lives and the rehabilitation of sexual offenders: Promises and problems. Aggression and Violent Behavior, 7, 513-528

Ward, T. \& Marshall, W. L. (2007) Narrative identity and offender rehabilitation. International Journal of Offender Therapy and Comparative Criminology, 51, 279297

Ward, T., Stewart, C. (2003). The relationship between human needs and criminogenic needs. Psychology, Crime \& Law, 9(2), 125-143

Wood , P. B. , Wilson, J. , \& Cochran , J. K. ( 1997 ). Nonsocial reinforcement and habitual criminal conduct: An extension of learning theory. Criminology , 35 , $335-$ 366 
